\title{
Deep-sea antibiotics exploitation: PROs and CONs
}

\author{
lyiola Olatunji Oladunjoye ${ }^{1} \mathbb{D}$, Joy Ginika Ikebuaso ${ }^{2} \mathbb{D}$, \\ Christian Tochukwu Agboeze ${ }^{3}\left(\mathbb{D}\right.$, Yusuf Amuda Tajudeen ${ }^{1}$ \\ ${ }^{1}$ Department of Microbiology, Faculty of Life Sciences, University of Ilorin, Ilorin, Nigeria \\ ${ }^{2}$ Department of Microbiology, Faculty of Natural Sciences, Chukwuemeka Odumegwu Ojukwu University, Ihiala, Nigeria \\ ${ }^{3}$ Department of Microbiology, Faculty of Biological Sciences, University of Nigeria, Nsukka, Nigeria
}

Antimicrobial resistance is an incubating pandemic that needs urgent alleviation as most known antibiotics are currently ineffective against a wide group of bacteria following the misuse of antibiotics. The increasing rate of resistivity of bacteria to known antibiotics is continuously destroying the effort made by scientists towards the discovering of antibiotics in past decades. Pharmaceutical industries have abandoned natural metabolite research from microorganism due to the lack of rediscovery and low metabolite production in known microbes around the environment [1]. Also, microorganisms that produce these important secondary metabolites cannot grow on culture media plates in the laboratory [1]. Following the constant demand for several drugs, scientist have been inspired to seek for solutions in untapped habitats like the sea and this has recorded positive discovery of novel Actinomycetes and Streptomyces species used to combat infectious disease.

Deep-sea is the furthermost ecosystem with much untapped natural biodiversity; its sediment contains important microbial diversity whose secondary metabolite can be utilised by man [2]. Irrespective of our limited knowledge of this ecosystem, they play a pivotal role in ecological balance and serve as one of the nurseries of life on earth [3]. Deep-sea peregrination has moved from geological to ecological to biological to physiological and currently, bioprospecting [3]. The exploitation of the sea is not a novel practice, but this has gained more scientific interest due to resource scarcity, improved technology [4] and partnership between governments, industries, and scientific researchers [3]. A noticeable alteration of the natural state of the deep-sea will directly influence other factors unifying the environment.

The quest for pure forms of organism that produces bioactive natural products has been the latest focus of scientific research as they harness these products and promote its application to combat antimicrobial resistance and other infections. It is no doubt that recent microbial discoveries in these untapped environments have led to novel compounds with hopeful bioactivities [1]. However, there is a need to clearly define what bioprospecting stands for and develop guidelines and criteria in adjudicating the consequence of scientific research on the natural biota in the sea [3]. It is very essential that the rate of exploitation and technology used during the process needs to be regulated to limit the pressure exerted on the lives below water. Bioprospecting needs adherence to technological, legal, economic, societal, and environmental policy to ensure its sustainability [4]. If these policies are not fully adopted by sea exploiters, there will be little or no resources to harness/utilise bringing us to our current era of over-exploitation of terrestrial microbe [1]. The current and future consequence of these exploitation need to be emphasised because pressure on any of the factors sustaining the earth disrupts the state of equilibrium of others.

\section{Conflict of interest: None declared}

\section{REFERENCES}

1. Hug JJ, Bader CD, Remškar M, et al. Concepts and methods to access novel antibiotics from actinomycetes. Antibiotics (Basel). 2018; 7(2), doi: 10.3390/antibiotics7020044, indexed in Pubmed: 29789481.

2. Sivalingam $P$, Hong $K$, Pote J, et al. Extreme environment: potential sources for new antibacterial and anticancer drug leads? Int J Microbiol. 2019; 2019: 5283948, doi: 10.1155/2019/5283948, indexed in Pubmed: 31354829.

3. Arico S, Salpin C. Bioprospecting of genetic resources in the deep seabed; Scientific, legal, and policy aspects. Industrial Biotech. 2005; 1(4): 260-282, doi: 10.1089/ind.2005.1.260.

4. Rademaekers K, Widerberg 0 , Svatikova K, van der Veen R, Panella E. Technology options for deep-seabed exploitation Tackling economic, environmental and societal challenges. STOA project carried out by Triple E Consulting and Milieu Ltd. at the request of the Science and Technology Options Assessment (STOA) Panel, within the Directorate-General for Parliamentary Research Services (DG EPRS) of the General Secretariat of the European Parliament. 2015 Mar. 